\title{
Effects of DL-Homocysteine Thiolactone on Cardiac Contractility, Coronary Flow, and Oxidative Stress Markers in the Isolated Rat Heart: The Role of Different Gasotransmitters
}

\author{
Vladimir Zivkovic, ${ }^{1}$ Vladimir Jakovljevic, ${ }^{1}$ Olga Pechanova, ${ }^{2}$ Ivan Srejovic, ${ }^{1}$ \\ Jovana Joksimovic, ${ }^{1}$ Dragica Selakovic, ${ }^{1}$ Nevena Barudzic, ${ }^{1}$ and Dragan M. Djuric ${ }^{3}$ \\ ${ }^{1}$ Department of Physiology, Faculty of Medical Sciences, University of Kragujevac, Kragujevac, Serbia \\ ${ }^{2}$ Institute of Normal and Pathological Physiology and Centre of Excellence for Examination of Regulatory Role of Nitric Oxide in \\ Civilization Diseases, Slovak Academy of Sciences, Bratislava, Slovakia \\ ${ }^{3}$ Institute of Medical Physiology "Richard Burian", Faculty of Medicine University of Belgrade, Belgrade, Serbia
}

Correspondence should be addressed to Vladimir Jakovljevic; drvladakgbg@yahoo.com

Received 7 June 2013; Revised 20 September 2013; Accepted 31 October 2013

Academic Editor: Zsolt Bagi

Copyright (C) 2013 Vladimir Zivkovic et al. This is an open access article distributed under the Creative Commons Attribution License, which permits unrestricted use, distribution, and reproduction in any medium, provided the original work is properly cited.

\begin{abstract}
Considering the adverse effects of DL-homocysteine thiolactone hydrochloride (DL-Hcy TLHC) on vascular function and the possible role of oxidative stress in these mechanisms, the aim of this study was to assess the influence of DL-Hcy TLHC alone and in combination with specific inhibitors of important gasotransmitters, such as L-NAME, DL-PAG, and PPR IX, on cardiac contractility, coronary flow, and oxidative stress markers in an isolated rat heart. The hearts were retrogradely perfused according to the Langendorff technique at a $70 \mathrm{~cm} \mathrm{H}_{2} \mathrm{O}$ and administered $10 \mu \mathrm{M}$ DL-Hcy TLHC alone or in combination with $30 \mu \mathrm{M} \mathrm{L}-$ NAME, $10 \mu \mathrm{M}$ DL-PAG, or $10 \mu \mathrm{M}$ PPR IX. The following parameters were measured: $d p / d t$ max, $d p / d t$ min, SLVP, DLVP, MBP, HR, and CF. Oxidative stress markers were measured spectrophotometrically in coronary effluent through TBARS, $\mathrm{NO}_{2}, \mathrm{O}_{2}{ }^{-}$, and $\mathrm{H}_{2} \mathrm{O}_{2}$ concentrations. The administration of DL-Hcy TLHC alone decreased $d p / d t$ max, SLVP, and CF but did not change any oxidative stress parameters. DL-Hcy TLHC with L-NAME decreased CF, $\mathrm{O}_{2}{ }^{-}, \mathrm{H}_{2} \mathrm{O}_{2}$, and TBARS. The administration of DL-Hcy TLHC with DL-PAG significantly increased $d p / d t$ max but decreased DLVP, CF, and TBARS. Administration of DL-Hcy TLHC with PPR IX caused a decrease in $d p / d t$ max, SLVP, HR, CF, and TBARS.
\end{abstract}

\section{Introduction}

Cardiovascular diseases (CVDs) are still the leading cause of morbidity and mortality among all racial and ethnic populations [1]. Most studies investigating this issue concluded that only a little more than half of the cases of CVDs can be linked with some of the classic risk factors [2]. Intensive research in this field in the last two decades has paid more attention to the sulphur-containing amino acid homocysteine (Hcy) as a risk factor for developing CVDs and labelled this molecule as the "cholesterol of the 21st century" [3]. Numerous epidemiological studies have shown a high association between hyperhomocysteinemia and increased risk for CVDs, thus promoting Hcy as a new and independent risk factor for these diseases $[4,5]$.
Several studies have shown that the L form of Hcy has the highest bioactive potential. However, the presence of a thiolactone group produces the highest toxicity of Hcy compounds, most likely through N-homocysteinylation [6] and inhibition of $\mathrm{Na}^{+}, \mathrm{K}^{+}$-ATPase [7]. The fate of Hcy thiolactone in cultures of human cells and its reactivity toward proteins and amino acids under physiological conditions were studied by Jakubowski [6]. The data suggested a mechanism by which Hcy, through its metabolic conversion to thiolactone, which in turn acylates proteins, can lead to cell damage resulting in pathology such as avascular disease. Hyperhomocysteinaemia represents a metabolic disorder caused by a deficiency of certain enzymes and/or vitamins that are involved in the homocysteine metabolic pathway. It causes accumulation of homocysteine in the blood $[8,9]$. It has been 
reported that homocysteine evokes endothelial dysfunction and impairment of nitric oxide (NO) bioavailability in animal models [10] and cell culture studies [11]. One possible mechanism of homocysteine's effects is the generation of hydrogen peroxide $\left(\mathrm{H}_{2} \mathrm{O}_{2}\right)$ [12] and the superoxide anion, which increases the oxidative degradation of NO [13]. The most widely known endothelium-derived relaxing factor, $\mathrm{NO}$, is released from endothelial cells in response to shear stress or the stimulation of different receptors for a variety of neurohumoral mediators on the endothelial cell surface [14].

Nitric oxide synthases (NOSs) are a family of enzymes catalysing the production of nitric oxide (NO) from Larginine. Nitric oxide (NO) impairs contractility [15], while an increased myocardial production of NO is proposed as a contributor to the progression of chronic cardiac failure [16]. Chronically failing hearts display an increased expression of nitric oxide synthase II (NOS II) [17], which leads to increased cardiac NO production [18]. Hemodynamic effects are accompanied by a significant decrease in nitrite outflow after $N^{\omega}$-Nitro-L-arginine methyl ester (L-NAME) administration $[19,20]$. Inactivation of nitric oxide (NO) by superoxide and other reactive oxygen species (ROS) seems to occur in conditions such as hypertension, hypercholesterolemia, diabetes, and cigarette smoking.

Hydrogen sulphide $\left(\mathrm{H}_{2} \mathrm{~S}\right)$ is a signalling molecule that belongs to the gasotransmitter family. $\mathrm{H}_{2} \mathrm{~S}$ is a potent vasodilator and has powerful anti-inflammatory, antioxidant and antiapoptotic effects [21-25], which are mediated by its ability to directly scavenge ROS and downregulate the ROS-producing enzymes. Three major endogenous sources of enzymatically produced $\mathrm{H}_{2} \mathrm{~S}$ are cystathionine beta synthase (CBS), cystathionine gamma lyase (CSE), whose expression was shown in the cardiovascular system, and 3-mercaptopyruvate sulfurtransferase (MST). DLPropargylglycine (DL-PAG) is an irreversible inhibitor of the $\mathrm{H}_{2} \mathrm{~S}$-synthesising enzyme cystathionine gamma lyase (CSE). Heme oxygenase (HO), a rate-limiting enzyme in heme metabolism, degrades heme into biliverdin/bilirubin, with the production of carbon monoxide $(\mathrm{CO})$ and free iron $(\mathrm{Fe})$. The products of heme metabolism produce various beneficial physiological effects, such as antioxidant effects, antiapoptotic effects, anti-inflammatory effects, vasodilation, cell cycle regulation, enhanced insulin sensitivity, adiponectin induction, and angiogenesis regulation [26, 27]. Heme oxygenases mainly include two isoenzymes: $\mathrm{HO}-1$ and $\mathrm{HO}-2$. $\mathrm{HO}-1$ is an inducible isoenzyme whose expression and activity can be upregulated by inducers or downregulated by inhibitors, such as zinc protoporphyrin IX (ZnPPR IX). By using DL-PAG as an irreversible inhibitor of CSE and/or ZnPPR IX as an HO-1 inhibitor, we could indirectly examine the production and thus a potential role in cardiac function and coronary circulation of $\mathrm{H}_{2} \mathrm{~S}$ and $\mathrm{CO}$.

Considering the data regarding the adverse effects of DLHcy TLHC on vascular function and the role of oxidative stress in these mechanisms, the aim of this study was to evaluate its influence on cardiac contractility, coronary flow, and oxidative stress markers in the isolated rat heart.

\section{Material and Methods}

The hearts of male Wistar albino rats $(n=48,12$ in each experimental group, BM 180-200 g) were excised and perfused according to the modified Langendorff technique at constant pressure conditions (Experimetria Ltd., Budapest, Hungary), as described previously [28]. Briefly, under ether anaesthesia, animals were premedicated with heparin as an anticoagulant and sacrificed by cervical dislocation (Schedule 1 of the Animals/Scientific Procedures, Act 1986, UK). After emergency thoracotomy and rapid cardiac arrest by superfusion with ice-cold isotonic saline, the hearts were rapidly excised; the aortas were cannulated and retrogradely perfused at the constant pressure (CPP) of $70 \mathrm{~cm} \mathrm{H}_{2} \mathrm{O}$. The composition of the nonrecirculating Krebs-Henseleit perfusate was as follows mM/L: $\mathrm{NaCl} 118, \mathrm{KCI} 4.7, \mathrm{CaCl}_{2} \cdot 2 \mathrm{H}_{2} \mathrm{O}$ 2.5, $\mathrm{MgSO}_{4} \cdot 7 \mathrm{H}_{2} \mathrm{O} 1.7, \mathrm{NaHCO}_{3} 25, \mathrm{KH}_{2} \mathrm{PO}_{4} 1.2$, glucose 11, and pyruvate 2 , equilibrated with $95 \% \mathrm{O}_{2}$ plus $5 \% \mathrm{CO}_{2}$ and warmed to $37^{\circ} \mathrm{C}(\mathrm{pH} 7.4)$. Immediately after normal heart rhythm returned, the sensor (transducer BS4 73-0184, Experimetria Ltd., Budapest, Hungary) was inserted through the newly damaged left atrium and mitral valve into the left ventricle for continuous monitoring of cardiac function.

2.1. Physiological Assay and Experimental Protocol. To test coronary vascular reactivity, all hearts were challenged by short-term occlusions (5-30 s), followed by a bolus injection of $5 \mathrm{mM} / \mathrm{L}$ adenosine $(60 \mu \mathrm{L}$ at a flow rate of $10 \mathrm{~mL} / \mathrm{min}$ to elicit maximum coronary flow (CF)) during the stabilisation period. Hearts were discarded if the flow did not increase by $100 \%$ over the control value for both tests (approximately 25\% of hearts). Coronary flow was measured using flowmetry. When the flow was considered stable (three measurements of the same values), coronary effluent samples were collected. Only groups of hearts in which the CPP/CF relationship was studied twice in the absence of drugs were included in the study. After perfusion in the absence of any medication (control conditions), hearts were perfused with:

(1) $10 \mu \mathrm{M}$ DL-Hcy thiolactone-hydrochloride (DL-Hcy TLHC);

(2) $10 \mu \mathrm{M}$ DL-Hcy TLHC $+30 \mu \mathrm{M}$ L-NAME $\left(N^{\omega}\right.$-Nitro$\mathrm{L}$-arginine methyl ester, an inhibitor of NOS);

(3) $10 \mu \mathrm{M}$ DL-Hcy TLHC $+10 \mu \mathrm{M}$ DL-PAG (DLPropargylglycine, an inhibitor of cystathionine gamma lyase-CSE);

(4) $10 \mu \mathrm{M}$ DL-Hcy TLHC $+10 \mu \mathrm{M}$ ZnPPR IX (protoporphyrin IX zinc, an inhibitor of HO-1) and compared to the respective controls.

By placing the sensor in the left ventricle, the following parameters of myocardial function were continuously registered:

(1) maximum rate of pressure development in the left ventricle ( $d p / d t$ max);

(2) minimum rate of pressure development in the left ventricle ( $d p / d t \mathrm{~min})$; 
(3) systolic left ventricular pressure (SLVP);

(4) diastolic left ventricular pressure (DLVP);

(5) mean blood pressure (MBP);

(6) heart rate (HR).

Coronary flow (CF) was measured using the flowmetric method.

All research procedures were approved by the Ethical Committee for Animal Welfare, Faculty of Medical Sciences, University of Kragujevac, Serbia.

2.2. Biochemical Assays. Oxidative stress parameters (index of lipid peroxidation measured as thiobarbituric acid reactive substances (TBARS), the superoxide anion radical $\mathrm{O}_{2}{ }^{-}$, hydrogen peroxide $\mathrm{H}_{2} \mathrm{O}_{2}$, and nitrite $\mathrm{NO}_{2}{ }^{-}$) were determined in coronary venous effluent samples using the spectrophotometric method (Specord S-600 Analytik Jena).

2.2.1. Index of Lipid Peroxidation (Thiobarbituric Acid Reactive Substances (TBARS)). The degree of lipid peroxidation in the coronary venous effluent was estimated by measuring thiobarbituric acid reactive substances (TBARS) using 1\% thiobarbituric acid (TBA) in $0.05 \mathrm{NaOH}$ incubated with the coronary effluent at $100^{\circ} \mathrm{C}$ for $15 \mathrm{~min}$ and read at $530 \mathrm{~nm}$. Krebs-Henseleit solution was used as a blank probe [29].

2.2.2. Nitrite Determination. Nitric oxide rapidly decomposes to form stable metabolite nitrite/nitrate products. The nitrite level $\left(\mathrm{NO}_{2}\right)$ was measured as an index of $\mathrm{NO}$ production using the Griess reagent. A total of $0.5 \mathrm{~mL}$ of perfusate was precipitated with $200 \mu \mathrm{L}$ of $30 \%$ sulphosalicylic acid, vortexed for $30 \mathrm{~min}$, and centrifuged at 3,000 $\times \mathrm{g}$. Equal volumes of the supernatant and Griess reagent, containing $1 \%$ sulphanilamide in 5\% phosphoric acid $/ 0.1 \%$ naphthalene ethylenediamine-dihydrochloride, were added, incubated for $10 \mathrm{~min}$ in the dark, and read at $543 \mathrm{~nm}$. The nitrite levels were calculated using sodium nitrite as the standard [30].

2.2.3. Determination of Superoxide Anion Radical. The level of the superoxide anion radical $\left(\mathrm{O}_{2}{ }^{-}\right)$was measured by Nitro Blue Tetrazolium (NBT) reaction in TRIS-buffer with coronary venous effluent and read at $530 \mathrm{~nm}$. Krebs-Henseleit solution was used as a blank probe [31].

2.2.4. Determination of $\mathrm{H}_{2} \mathrm{O}_{2}$. The measurement of $\mathrm{H}_{2} \mathrm{O}_{2}$ is based on the oxidation of Phenol Red by $\mathrm{H}_{2} \mathrm{O}_{2}$ in a reaction catalysed by horseradish peroxidase (HRPO) [32]. A volume of $200 \mu \mathrm{L}$ of perfusate was precipitated with $800 \mu \mathrm{L}$ of fresh Phenol Red solution (PRS), along with $10 \mu \mathrm{L}$ of $1: 20 \mathrm{HRPO}$ (made ex tempore). An adequate volume of Krebs-Henseleit solution was used for a blank probe (instead of coronary venous effluent). The level of $\mathrm{H}_{2} \mathrm{O}_{2}$ was measured at $610 \mathrm{~nm}$.

2.3. Drugs. All drugs were purchased from Sigma-Aldrich Chemie GmbH, Germany.
2.4. Statistical Analysis. Values are expressed as the mean \pm SE. Statistical analysis was performed by the Wilcoxon test. $P$ values less than 0.05 were considered significant.

\section{Results}

3.1. The Effects of DL-Hcy TLHC, DL-Hcy TLHC + L-NAME, DL-Hcy TLHC + DL-PAG, or DL-Hcy TLHC + PPR IX on Myocardial Function Parameters in the Isolated Rat Heart. The administration of DL-Hcy TLHC $(10 \mu \mathrm{M})$ induced a significant decrease in $d p / d t \max (P<0.05)$, SLVP $(P<0.01)$, and CF $(P<0.05)$ compared with control conditions. Other measured myocardial function parameters remained unchanged (Table $1(\mathrm{a})$ ). Perfusion with DL-Hcy TLHC $(10 \mu \mathrm{M})+$ L-NAME $(30 \mu \mathrm{M})$ significantly decreased only CF $(P<0.01)$ (Table $1(\mathrm{~b}))$. The application of DL-Hcy $(10 \mu \mathrm{M})+$ DL-PAG $(10 \mu \mathrm{M})$ induced a significant increase in $d p / d t$ max $(P<0.05)$, a significant decrease in DLVP $(P<$ $0.01)$, and a significant decrease in CF $(P<0.05)$ compared with control conditions. In contrast, this compound did not significantly affect $d p / d t$ min, SLVP, HR, or MBP (Table 1(c)). The administration of DL-Hcy TLHC $(10 \mu \mathrm{M})+$ PPR IX $(10 \mu \mathrm{M})$ induced a significant decrease in $d p / d t \max (P<$ 0.05), SLVP $(P<0.05)$, HR $(P<0.05)$, and CF $(P<$ $0.05)$ compared with the control conditions; $d p / d t$ min was the only significantly increased parameter in this group of experiments under the influence of DL-Hcy TLHC $(10 \mu \mathrm{M})+$ PPR IX $(10 \mu \mathrm{M})(P<0.05)$.

3.2. The Effects of DL-Hcy TLHC, DL-Hcy TLHC + L-NAME, DL-Hcy TLHC + DL-PAG, or DL-Hcy TLHC + PPR IX on Oxidative Stress Markers in the Isolated Rat Heart. Perfusion with DL-Hcy TLHC $(10 \mu \mathrm{M})$ did not induce significant changes in any oxidative stress markers $\left(\mathrm{O}_{2}{ }^{-}, \mathrm{H}_{2} \mathrm{O}_{2}, \mathrm{NO}_{2}{ }^{-}\right.$, and TBARS) compared with control conditions (Table 2(a)). Perfusion with DL-Hcy TLHC $(10 \mu \mathrm{M})+$ L-NAME $(30 \mu \mathrm{M})$ induced significant decreases in $\mathrm{O}_{2}{ }^{-}(P<0.05), \mathrm{H}_{2} \mathrm{O}_{2}$ $(P<0.05)$, and TBARS $(P<0.01)$ compared with control conditions (Table 2(b)).

After heart perfusion with DL-Hcy $(10 \mu \mathrm{M})+$ DL-PAG $(10 \mu \mathrm{M})$, there was no significant difference in the levels of oxidative stress markers, except in the TBARS values, which were significantly decreased $(P<0.05)$ compared with control conditions (Table 2(c)). After heart perfusion with DL-Hcy TLHC $(10 \mu \mathrm{M})+$ PPR IX $(10 \mu \mathrm{M})$, there was no significant difference in the levels of oxidative stress markers, except in the TBARS values which were significantly decreased $(P<0.05)$ compared with control conditions (Table 2(d)).

\section{Discussion}

The aim of the present study was to assess the influence of acute administration of DL-Hcy TLHC and DL-Hcy TLHC in combination with specific inhibitors of important gasotransmitters, such as L-NAME (an inhibitor of NO production via inhibition of NOS), DL-PAG (an inhibitor of $\mathrm{H}_{2} \mathrm{~S}$ production via inhibition of CSE), and PPR IX (an inhibitor of CO 
TABLE 1: The effects of DL-Hcy TLHC (a), DL-Hcy TLHC + L-NAME (b), DL-Hcy TLHC + DL-PAG (c), or DL-Hcy TLHC + PPR IX (d) on heart variables in the isolated rat heart $(n=12$, each substance $10 \mu \mathrm{M}$, except L-NAME $(30 \mu \mathrm{M}))$.

(a)

\begin{tabular}{|c|c|c|c|c|c|c|c|}
\hline & $\begin{array}{c}d p / d t \max \\
(\mathrm{mmHg} / \mathrm{s})\end{array}$ & $\begin{array}{l}d p / d t \min \\
(\mathrm{mmHg} / \mathrm{s})\end{array}$ & $\begin{array}{c}\text { SLVP } \\
(\mathrm{mmHg})\end{array}$ & $\begin{array}{c}\text { DLVP } \\
(\mathrm{mmHg})\end{array}$ & $\begin{array}{c}\mathrm{MBP} \\
(\mathrm{mmHg})\end{array}$ & HR (bpm) & $\begin{array}{c}\text { Flow } \\
(\mathrm{mL} / \mathrm{min})\end{array}$ \\
\hline $\begin{array}{l}\text { Control } \\
(X \pm S E)\end{array}$ & $2590.8 \pm 160.7$ & $-836.3 \pm 358.7$ & $70.1 \pm 3.8$ & $7.1 \pm 3.5$ & $50.4 \pm 0.3$ & $258.2 \pm 16.2$ & $11.5 \pm 0.6$ \\
\hline $\begin{array}{l}\text { DL-Hcy } \\
\text { TLHC } \\
(X \pm S E)\end{array}$ & $2222.8 \pm 231.0^{*}$ & $-1292.8 \pm 177.9$ & $53.9 \pm 4.8^{* *}$ & $2.9 \pm 0.8$ & $50.3 \pm 0.2$ & $265.9 \pm 15.3$ & $10.7 \pm 0.6^{*}$ \\
\hline
\end{tabular}

The values are expressed as the mean $\pm \mathrm{SE} .{ }^{*}$ Statistical significance $(P<0.05),{ }^{* *}$ high statistical significance $(P<0.01)$.

(b)

\begin{tabular}{lccccccc}
\hline & $\begin{array}{c}d p / d t \max \\
(\mathrm{mmHg} / \mathrm{s})\end{array}$ & $\begin{array}{c}d p / d t \mathrm{~min} \\
(\mathrm{mmHg} / \mathrm{s})\end{array}$ & $\begin{array}{c}\text { SLVP } \\
(\mathrm{mmHg})\end{array}$ & $\begin{array}{c}\text { DLVP } \\
(\mathrm{mmHg})\end{array}$ & $\begin{array}{c}\text { MBP } \\
(\mathrm{mmHg})\end{array}$ & $\begin{array}{c}\text { HR }(\mathrm{bpm}) \\
(\mathrm{mL} / \mathrm{min})\end{array}$ \\
\hline $\begin{array}{l}\text { Control } \\
(X \pm \mathrm{SE})\end{array}$ & $1856.33 \pm 259.37$ & $-1112.63 \pm 161.45$ & $67.38 \pm 5.23$ & $16.10 \pm 4.12$ & $51.25 \pm 1.78$ & $229.65 \pm 7.82$ & $11.10 \pm 0.84$ \\
$\begin{array}{l}\text { DL-Hcy } \\
\text { TLHC + }\end{array}$ & $1691.35 \pm 392.89$ & $-1104.23 \pm 318.24$ & $57.11 \pm 8.21$ & $14.50 \pm 3.76$ & $50.16 \pm 0.69$ & $225.56 \pm 7.33$ & $8.10 \pm 1.06^{* *}$ \\
$\begin{array}{l}\text { L-NAME } \\
(X \pm \text { SE })\end{array}$ & & & & & & & \\
\hline
\end{tabular}

The values are expressed as the mean $\pm \mathrm{SE} .{ }^{* *}$ High statistical significance $(P<0.01)$.

(c)

\begin{tabular}{|c|c|c|c|c|c|c|c|}
\hline & $\begin{array}{l}d p / d t \max \\
(\mathrm{mmHg} / \mathrm{s})\end{array}$ & $\begin{array}{l}d p / d t \min \\
(\mathrm{mmHg} / \mathrm{s})\end{array}$ & $\begin{array}{c}\text { SLVP } \\
(\mathrm{mmHg})\end{array}$ & $\begin{array}{c}\text { DLVP } \\
(\mathrm{mmHg})\end{array}$ & $\begin{array}{c}\text { MBP } \\
(\mathrm{mmHg})\end{array}$ & HR (bpm) & $\begin{array}{c}\text { Flow } \\
(\mathrm{mL} / \mathrm{min})\end{array}$ \\
\hline $\begin{array}{l}\text { Control } \\
(X \pm S E)\end{array}$ & $1660.81 \pm 214.11$ & $-1193.98 \pm 192.70$ & $63.73 \pm 3.86$ & $12.63 \pm 3.77$ & $50.55 \pm 0.14$ & $241.38 \pm 20$ & $9.67 \pm 0.40$ \\
\hline $\begin{array}{l}\text { DL-Hcy } \\
\text { TLHC + } \\
\text { DL-PAG } \\
(X \pm S E)\end{array}$ & $1989.60 \pm 230.29^{*}$ & $-1356.66 \pm 219.02$ & $62.65 \pm 6.08$ & $7.21 \pm 2.64^{* *}$ & $50.76 \pm 0.14$ & $205.46 \pm 34.4$ & $8.56 \pm 0.34^{*}$ \\
\hline
\end{tabular}

The values are expressed as the mean $\pm \mathrm{SE} .{ }^{*}$ Statistical significance $(P<0.05),{ }^{* *}$ high statistical significance $(P<0.01)$.

(d)

\begin{tabular}{|c|c|c|c|c|c|c|c|}
\hline & $\begin{array}{l}d p / d t \max \\
(\mathrm{mmHg} / \mathrm{s})\end{array}$ & $\begin{array}{l}d p / d t \min \\
(\mathrm{mmHg} / \mathrm{s})\end{array}$ & $\begin{array}{c}\text { SLVP } \\
(\mathrm{mmHg})\end{array}$ & $\begin{array}{c}\text { DLVP } \\
(\mathrm{mmHg})\end{array}$ & $\begin{array}{c}\mathrm{MBP} \\
(\mathrm{mmHg})\end{array}$ & HR (bpm) & $\begin{array}{c}\text { Flow } \\
(\mathrm{mL} / \mathrm{min})\end{array}$ \\
\hline $\begin{array}{l}\text { Control } \\
(X \pm \mathrm{SE})\end{array}$ & $1671.76 \pm 94.89$ & $-748.85 \pm 67.71$ & $57.30 \pm 0.87$ & $1.15 \pm 0.45$ & $49.70 \pm 0.73$ & $237.01 \pm 8.13$ & $10.50 \pm 0.39$ \\
\hline $\begin{array}{l}\text { DL-Hcy } \\
\text { TLHC + } \\
\text { PPR IX } \\
(X \pm \text { SE })\end{array}$ & $819.91 \pm 31.26^{*}$ & $-396.76 \pm 29.62^{*}$ & $22.26 \pm 2.48^{*}$ & $1.86 \pm 0.44$ & $50.05 \pm 0.72$ & $107.50 \pm 7.20^{*}$ & $5.63 \pm 0.38^{*}$ \\
\hline
\end{tabular}

The values are expressed as the mean \pm SE. ${ }^{*}$ Statistical significance $(P<0.05)$.

production via inhibition of $\mathrm{HO}-1$ ), on cardiac contractility, coronary flow, and oxidative stress markers in the isolated rat heart. This study is partly a result of our investigation on the effects of Hcy and Hcy-related compounds on the cardiovascular system with special focus on gasotransmitters.

In the first part of our research, we focused on the effects of investigated compounds on dynamic parameters of myocardial function $(d p / d t \max , d p / d t$ min, SLVP, DLVP, MBP, HR, and CF). Our data showed that the administration of $10 \mu \mathrm{M}$ DL-Hcy TLHC induced depression of cardiac contractility in the isolated rat heart, manifested as a decrease in $d p / d t$ max. The administration of DL-Hcy TLHC also induced a decrease in SLVP.
The results of this study correlate with the results of Moshal et al. [33], who found that an excess of Hcyinduced fibrosis and endothelial myocyte disconnection led to a decrease in myocardial contractility in a mouse model. Cardiomyocytes express NMDA receptors whose activation increases oxidative stress and $\mathrm{Ca}^{2+}$ load in the mitochondria, leading to cell death [34]. Hcy induces contractile dysfunction by an unknown mechanism. Moshal et al. [35] demonstrated a correlation between cardiomyocyte NMDA receptors, mitochondrial matrix metalloproteinases (mMMPs), and hyperhomocysteinemia. They showed that Hcy caused contractile dysfunction by activating mMMP and NMDA-R1. Our results show a decrease in SLVP by acute administration 
TABLE 2: The effects of DL-Hcy TLHC (a), DL-Hcy TLHC + L-NAME (b), DL-Hcy TLHC + DL-PAG (c), or DL-Hcy TLHC + PPR IX (d) on oxidative stress markers in the isolated rat heart $(n=12$, each substance $10 \mu \mathrm{M}$, except L-NAME $(30 \mu \mathrm{M}))$.

(a)

\begin{tabular}{lcccc}
\hline & $\mathrm{O}_{2}{ }^{-}(\mathrm{nmol} / \mathrm{mL})$ & $\mathrm{H}_{2} \mathrm{O}_{2}(\mathrm{nmol} / \mathrm{mL})$ & $\mathrm{NO}_{2}{ }^{-}(\mathrm{nmol} / \mathrm{mL})$ & $\mathrm{TBARS}(\mu \mathrm{mol} / \mathrm{mL})$ \\
\hline Control $(X \pm \mathrm{SE})$ & $19.97 \pm 0.45$ & $20.28 \pm 0.04$ & $23.14 \pm 1.17$ & $26.20 \pm 0.38$ \\
DL-Hcy TLHC $(X \pm \mathrm{SE})$ & $20.19 \pm 0.47$ & $20.23 \pm 0.03$ & $23.52 \pm 1.13$ & $25.88 \pm 0.91$ \\
\hline
\end{tabular}

The values are expressed as the mean \pm SE.

(b)

\begin{tabular}{lcccc}
\hline & $\mathrm{O}_{2}{ }^{-}(\mathrm{nmol} / \mathrm{mL})$ & $\mathrm{H}_{2} \mathrm{O}_{2}(\mathrm{nmol} / \mathrm{mL})$ & $\mathrm{NO}_{2}{ }^{-}(\mathrm{nmol} / \mathrm{mL})$ & $\mathrm{TBARS}(\mu \mathrm{mol} / \mathrm{mL})$ \\
\hline Control $(X \pm \mathrm{SE})$ & $40.70 \pm 6.24$ & $34.55 \pm 2.45$ & $23.74 \pm 1.00$ & $27.02 \pm 3.04$ \\
DL-Hcy TLHC + L-NAME $(X \pm \mathrm{SE})$ & $23.33 \pm 4.45^{*}$ & $24.70 \pm 3.03^{*}$ & $23.30 \pm 0.51$ & $17.46 \pm 2.63^{* *}$ \\
\hline
\end{tabular}

The values are expressed as the mean \pm SE. ${ }^{*}$ Statistical significance $(P<0.05),{ }^{* *}$ high statistical significance $(P<0.01)$.

(c)

\begin{tabular}{lcccc}
\hline & $\mathrm{O}_{2}{ }^{-}(\mathrm{nmol} / \mathrm{mL})$ & $\mathrm{H}_{2} \mathrm{O}_{2}(\mathrm{nmol} / \mathrm{mL})$ & $\mathrm{NO}_{2}{ }^{-}(\mathrm{nmol} / \mathrm{mL})$ & $\mathrm{TBARS}(\mu \mathrm{mol} / \mathrm{mL})$ \\
\hline Control $(X \pm \mathrm{SE})$ & $21.53 \pm 3.74$ & $30.78 \pm 1.52$ & $23.88 \pm 1.61$ & $22.50 \pm 3.00$ \\
DL-Hcy TLHC + DL-PAG $(X \pm \mathrm{SE})$ & $21.55 \pm 4.18$ & $29.89 \pm 1.05$ & $23.75 \pm 1.40$ & $11.97 \pm 7.42^{*}$ \\
\hline
\end{tabular}

The values are expressed as the mean \pm SE. ${ }^{*}$ Statistical significance $(P<0.05)$.

(d)

\begin{tabular}{lcccc}
\hline & $\mathrm{O}_{2}{ }^{-}(\mathrm{nmol} / \mathrm{mL})$ & $\mathrm{H}_{2} \mathrm{O}_{2}(\mathrm{nmol} / \mathrm{mL})$ & $\mathrm{NO}_{2}{ }^{-}(\mathrm{nmol} / \mathrm{mL})$ & $\mathrm{TBARS}(\mu \mathrm{mol} / \mathrm{mL})$ \\
\hline Control $(X \pm \mathrm{SE})$ & $30.69 \pm 4.97$ & $25.28 \pm 1.12$ & $23.62 \pm 0.53$ & $21.54 \pm 0.46$ \\
DL-Hcy TLHC + PPR IX $(X \pm \mathrm{SE})$ & $16.84 \pm 2.58$ & $11.42 \pm 0.26^{*}$ & $22.31 \pm 0.80$ & $20.96 \pm 0.23$ \\
\hline
\end{tabular}

The values are expressed as the mean \pm SE. ${ }^{*}$ Statistical significance $(P<0.05)$.

of DL-Hcy TLHC, in accordance with the results of Zivkovic et al. [28], who found that left ventricular systolic function significantly decreased after acute administration of Hcy compounds in rats. However, it is still unclear how Hcy compounds cause left ventricular systolic dysfunction.

Furthermore, our results show that DL-Hcy TLHC decreased SLVP in the isolated rat heart, in accordance with the results of previous investigations of acute and chronic models of hyperhomocysteinemia [28, 36]. Other cardiodynamic parameters were not significantly different under the influence of DL-Hcy TLHC (Table 1(a)).

DL-Hcy TLHC causes 10-fold increases in plasma homocysteine levels [37], according to the definition of referential ranges proposed in human and experimental models. Consequently, it would be expected that administration of DL-Hcy TLHC is more toxic than Hcy alone. However, Hcy may induce oxidative damage of endothelial cells, promote vascular smooth muscle growth, and inhibit regeneration of endothelial cells [38].

The inhibition of endothelial cell growth may be the result of methylation inhibition by Hcy [39]. In addition, Hcy may affect blood clotting mechanisms, thereby enchasing a prothrombotic state [40]. However, in the most cited experiments that led to this hypothesis, nonphysiological concentrations of Hcy (1-10 mmol/L) showed similar effects with cysteine or 2-mercaptoethanol [40,41]. Although effects of Hcy on growth and methylation were found at physiological Hcy concentrations, these effects could only be observed in the presence of high levels of adenosine [39]. In this study,
DL-Hcy TLHC did not affect cardiodynamic variables such as $d p / d t \min$, DLVP, MBP, and HR.

In our research, acute administration of DL-Hcy TLHC did not significantly affect HR, but there are studies suggesting that chronic application of Hcy increased HR in rats by decreasing the elastin/collagen ratio in the left ventricle $[42,43]$. Additionally, acute administration of DL-Hcy does not affect HR [44]. The acute administration of Hcyrelated compounds in this model does not achieve sufficient concentrations to increase LV collagen expression and cause endocardial precapillary and interstitial fibrosis [42].

In the present study, we showed that DL-Hcy TLHC alone and in combination with L-NAME, DL-PAG, or PPR IX caused vasoconstriction and a consequent decrease in CF. One possible mechanism by which these compounds contribute to vasoconstriction is impaired relaxation of the vascular muscle. As will be described below, $\mathrm{NO}_{2}{ }^{-}$as an indicator of NO production did not change significantly after the administration of any compound that we investigated. Based on this result, it can be suggested that in this experimental model, vasoconstriction could be induced mainly by acute effects of DL-Hcy TLHC and seems to be independent of $\mathrm{NO}$ release or the release of $\mathrm{H}_{2} \mathrm{~S}$ and $\mathrm{CO}$, as discussed below. However, studies investigating aortas in rats showed that the $\mathrm{HO}-1 / \mathrm{CO}$ pathway can have a role in the regulation of vascular tone [45].

The administration of L-NAME (an inhibitor of NOS) in combination with DL-Hcy TLHC was used to examine a potential effect of $\mathrm{NO}$ on cardiodynamic parameters and 
its influence on oxidative stress. The application of DLHcy TLHC induced significant changes in $d p / d t$ max, SLVP, and CF, while the administration of DL-Hcy TLHC + LNAME only affected CF, which decreased significantly. Hcythiolactone is generated in an error-editing reaction of protein biosynthesis when Hcy is selected instead of methionine by methionyl-tRNA synthetase10. Hcy-thiolactone, known to be cytotoxic in experimental animals and cell cultures, is detrimental mostly because of its ability to form isopeptide bonds with protein lysine residues (N-homocysteinylation) $[6,39,46]$, which impairs or alters the protein function $[47-$ 50]. N-homocysteinylation increases protein susceptibility to oxidative damage [49] via a thiyl radical mechanism [51], causes formation of toxic amyloid-like protofibrils [52], and induces an autoimmune response [53]. Additionally, $\mathrm{N}$-homocysteinylation can play a role in atherothrombosis through the accumulation of prothrombotic N-Hcyfibrinogen [50] in CBS-deficient patients [54] and the accumulation of IgG anti-N-Hcy-protein autoantibodies in cardiovascular disease [55] and stroke [56] patients.

Originally discovered ex vivo in cultured human fibroblasts and endothelial cells, Hcy-thiolactone [57-59] is known to occur in vivo in humans and mice and to increase in nutritional or genetic hyperhomocysteinemia. Human umbilical endothelial cells have been reported to possess $\mathrm{Hcy}$-thiolactone hydrolysing activity [38]. With regard to this fact, our aim was to evaluate the effects of DL-Hcy TLHC in the presence of NOS blockade by L-NAME. It seems that L-NAME abolished the effects of DL-Hcy TLHC on all cardiodynamic parameters except CF (Table 1(b)), suggesting that NOS blockade expresses protective effects in the heart via the improvement of contractile function compared to the application of DL-Hcy TLHC alone (Table 1(a)). Additional lowering of CF by simultaneous application of DL-Hcy TLHC and L-NAME compared to DL-Hcy TLHC alone can be a consequence of NO blockade (caused by L-NAME) and vasoconstriction of coronary vessels.

We investigated the influence of $\mathrm{CO}$ by blocking endogenous production of this gasotransmitter via $\mathrm{HO}$ using $\mathrm{ZnPPR}$ IX. Similarly, DL-Hcy TLHC alone and DL-Hcy TLHC + PPR IX induced decreases in $d p / d t$ max, SLVP, and CF. The combination of these compounds also affected $d p / d t \min$ and HR. There was an increase in $d p / d t$ min approaching to the zero level, which shows an impaired cardiac contractility. HR most likely decreased due to the prolongation of action potentials and the reduction of the sinus rhythm rate. Our results for $\mathrm{HR}$, (Table $1(\mathrm{~d})$ ) but not cardiac contractility, are similar to those of Abramochkin et al. [60].

In the heart, $\mathrm{H}_{2} \mathrm{~S}$ is produced in the myocardium fibroblasts and blood vessels from L-cysteine by the enzyme CSE, which exerts an important effect on physiological and pathophysiological processes. The role of $\mathrm{H}_{2} \mathrm{~S}$ has been investigated by using two main approaches: inhibiting endogenous $\mathrm{H}_{2} \mathrm{~S}$ and administrating exogenous $\mathrm{H}_{2} \mathrm{~S}$, mainly using $\mathrm{NaHS}$ as a donor. In this research, we used DL-PAG to inhibit endogenous production of $\mathrm{H}_{2} \mathrm{~S}$. $\mathrm{H}_{2} \mathrm{~S}$-induced vasodilation is hypothesised to occur in ATP-sensitive potassium channels $\left(\mathrm{K}_{\mathrm{ATP}}\right)$, thus increasing cGMP levels in tissues. Bucci et al. suggest that $\mathrm{H}_{2} \mathrm{~S}$ relaxes blood vessels by modulating cGMP levels [61]. Our results show a significant decrease in DLVP values, which correlates with the results obtained by Huang et al. [62], while $d p / d t$ max values were opposite to those in the mentioned study (Table $1(\mathrm{c})$ ). The reasons for these differences in $d p / d t$ max levels remain unknown.

In the second part of our investigation, we explored whether acute administration of DL-Hcy.

TLHC and its combination with L-NAME, DL-PAG, or PPR IX promoted oxidative stress in the isolated rat heart by measuring oxidative stress parameters $\left(\mathrm{O}_{2}{ }^{-}, \mathrm{H}_{2} \mathrm{O}_{2}, \mathrm{NO}_{2}{ }^{-}\right.$, and TBARS). In our previous research [35], there were no statistically significant changes in redox status in the isolated rat heart treated with DL-Hcy TLHC, which correlates with the results of the present study (Table 2(a)).

Additional application of DL-Hcy TLHC and L-NAME was followed by a significant reduction of all oxidative stress parameters, except $\mathrm{NO}_{2}{ }^{-}$(Table 2(b)). This result is in accordance with some of our previous data $[63,64]$ showing decreased production of ROS after NOS inhibition following acute administration. This result can be a direct consequence of decreased $\mathrm{O}_{2}{ }^{-}$production due to NOS inhibition, which leads to the direct lowering of $\mathrm{H}_{2} \mathrm{O}_{2}$ content and decreased global oxidative damage, measured as TBARS. The limitation of this study lies in the low-dose acute administration. We assume that chronic administration and higher exposure doses could result in different dynamics of ROS (increased generation of ROS).

Recently, $\mathrm{H}_{2} \mathrm{~S}$ has been shown to protect rat cortical neurons from oxidative insult by stimulating GSH synthesis [65], reducing production of peroxynitrite [23], and reducing $\mathrm{H}_{2} \mathrm{O}_{2}$ [66]. It is important to note that so far, the antioxidant properties of $\mathrm{H}_{2} \mathrm{~S}$ have been shown in the central nervous system [24] as a consequence of CBS action. Furthermore, recent results from Módis et al. [67] suggest antioxidant properties of this molecule due to the action of 3-mercaptopyruvate sulfurtransferase (3-MST), a novel enzyme identified in $\mathrm{H}_{2} \mathrm{~S}$-generating systems. The antioxidant properties of $\mathrm{H}_{2} \mathrm{~S}$ produced in mitochondria are specific [68]. This intracellular action reduces intracellular oxidative stress parameters, with special focus on reducing oxidation of cysteine residues contained in intracellular enzymes [69]. Moreover, this interaction is reciprocal; the increased ROS production inactivates $\mathrm{H}_{2} \mathrm{~S}[70,71]$. Interestingly, there are very limited data on the interaction between redox balance and the activity of CSE, a dominant $\mathrm{H}_{2} \mathrm{~S}$-producing enzyme in the cardiovascular system. According to our data (Table 2(c)), this effect is only present on the level of global oxidative damage, presented as TBARS. Namely, the DL-Hcy TLHC-induced changes of some oxidative stress parameters were not significantly affected by the simultaneous application of DL-Hcy TLHC + DL-PAG (an inhibitor of CSE). This result, which can be discussed as a consequence of CSE inhibition, shows an insignificant role of $\mathrm{H}_{2} \mathrm{~S}$ produced by this enzyme in redox balance in the isolated rat heart.

$\mathrm{CO}$ is a gasotransmitter with a similar capacity as NO to bind heme proteins, with many common downstreamsignalling pathways and functions. However, the role of $\mathrm{CO}$ in the presence or absence of NO may be unpredictable 
and diverse, depending on the concentration and tissue type [72]. One recent study by Soni et al. [73] showed a reduced $\mathrm{I} / \mathrm{R}$ injury in the isolated rat heart under the influence of an exogenous $\mathrm{CO}$ donor in the presence of L-NAME. This result suggests that $\mathrm{CO}$-induced cardioprotection is completely independent of NO. Our experimental model is focused on endogenous production of $\mathrm{CO}$ and its role in heart function. In addition, in our research, gasotransmitters are investigated only as a part of the heart response to DLHcy TLHC application. Additional blockade of endogenous CO production by PPR IX does not significantly change the primary effects of DL-Hcy TLHC on oxidative stress parameters. Only $\mathrm{H}_{2} \mathrm{O}_{2}$ was reduced by the simultaneous application of DL-Hcy TLHC + PPR IX (Table 2(c)), which made us conclude that this pathway did not contribute significantly to redox balance under the primary influence of the most toxic Hcy compound, DL-Hcy TLHC.

\section{Conclusions}

In summary, our findings clearly suggest that acute administration of DL-Hcy TLHC induces significant reduction of CF and partly of heart contractility, which confirms its cardiodepressive effect. The simultaneous application of different inhibitors of important cardiovascular gasotransmitters with DL-Hcy TLHC shows that additional HO-1 inhibition induces more powerful effects than NOS or CSE inhibition. The inhibition of $\mathrm{CO}$ production significantly increases DL-Hcy TLHC-induced effects on cardiodynamic parameters, while NOS and CSE inhibition only affects CF. Our results also suggest that acute administration of DL-Hcy TLHC and different gasotransmitter inhibitors does not show prooxidant potential. Furthermore, we did not find a link between cardiac dysfunction and oxidative stress after acute administration of DL-Hcy TLHC. Similar to our recent study, the data suggest that negative effects of DL-Hcy TLHC on myocardium do not necessarily involve oxidative stress.

\section{Conflict of Interests}

All authors of the present paper disclose no actual or potential conflicts of interest, including any financial, personal, or other relationships with people or organisations.

\section{Acknowledgments}

This work is supported by Grant no. 175043 from the Ministry of Science and Technical Development of the Republic of Serbia, COST Action BM1005 "European Network on Gasotransmitters," and Junior Project 04/2011, Faculty of Medical Sciences, University of Kragujevac, Serbia.

\section{References}

[1] S. C. Smith Jr, A. Collins, R. Ferrari et al., "Our time: a call to save preventable death from cardiovascular disease (heart disease and stroke)," Journal of the American College of Cardiology, vol. 60, no. 22, pp. 2343-2348, 2012.
[2] P. W. F. Wilson, R. B. D’Agostino, D. Levy, A. M. Belanger, H. Silbershatz, and W. B. Kannel, "Prediction of coronary heart disease using risk factor categories," Circulation, vol. 97, no. 18, pp. 1837-1847, 1998.

[3] H. M. Heneghan and S. Sultan, "Homocysteine, the cholesterol of the 21st century. Impact of hyperhomocysteinemia on patency and amputation-free survival after intervention for critical limb ischemia," Journal of Endovascular Therapy, vol. 15, no. 4, pp. 399-407, 2008.

[4] E. D. Kaplan, "Association between homocyst(e)ine levels and risk of vascular events," Drugs of Today, vol. 39, no. 3, pp. 175191, 2003.

[5] The Homocysteine Studies Collaboration, "Homocysteine and risk of ischemic heart disease and stroke: a meta-analysis," The Journal of the American Medical Association, vol. 288, no. 16, 2015.

[6] H. Jakubowski, "Metabolism of homocysteine thiolactone in human cell cultures: possible mechanism for pathological consequences of elevated homocysteine levels," The Journal of Biological Chemistry, vol. 272, no. 3, pp. 1935-1942, 1997.

[7] A. Rasić-Marković, O. Stanojlović, D. Hrncić et al., "The activity of erythrocyte and brain $\mathrm{Na}^{+} / \mathrm{K}^{+}$and $\mathrm{Mg}^{2+}$-ATPases in rats subjected to acute homocysteine and homocysteine thiolactone administration," Molecular and Cellular Biochemistry, vol. 327, no. 1-2, pp. 39-45, 2009.

[8] H. Refsum, P. M. Ueland, O. Nygård, and S. E. Vollset, "Homocysteine and cardiovascular disease," Annual Review of Medicine, vol. 49, pp. 31-62, 1998.

[9] R. H. Allen, S. P. Stabler, D. G. Savage, and J. Lindenbaum, "Metabolic abnormalities in cobalamin (vitamin B12) and folate deficiency," The FASEB Journal, vol. 7, no. 14, pp. 1344-1353, 1993.

[10] L. A. Harker, R. Ross, S. J. Slichter, and C. R. Scott, "Homocystine induced arteriosclerosis. The role of endothelial cell injury and platelet response in its genesis," Journal of Clinical Investigation, vol. 58, no. 3, pp. 731-741, 1976.

[11] R. T. Wall, J. M. Harlan, L. A. Harker, and G. E. Striker, "Homocysteine-induced endothelial cell injury in vitro: a model for the study of vascular injury," Thrombosis Research, vol. 18, no. 1-2, pp. 113-121, 1980.

[12] G. Starkebaum and J. M. Harlan, "Endothelial cell injury due to copper-catalyzed hydrogen peroxide generation from homocysteine," Journal of Clinical Investigation, vol. 77, no. 4, pp. 1370-1376, 1986.

[13] D. Lang, M. B. Kredan, S. J. Moat et al., "Homocysteine-induced inhibition of endothelium-dependent relaxation in rabbit aorta: role for superoxide anions," Arteriosclerosis, Thrombosis, and Vascular Biology, vol. 20, no. 2, pp. 422-427, 2000.

[14] R. A. Cohen and P. M. Vanhoutte, "Endothelium-dependent hyperpolarization: beyond nitric oxide and cyclic GMP," Circulation, vol. 92, no. 11, pp. 3337-3349, 1995.

[15] M. Flesch, H. Kilter, B. Cremers et al., "Acute effects of nitric oxide and cyclic GMP on human myocardial contractility," Journal of Pharmacology and Experimental Therapeutics, vol. 281, no. 3, pp. 1340-1349, 1997.

[16] W. J. Paulus, “The role of nitric oxide in the failing heart," Heart Failure Reviews, vol. 6, no. 2, pp. 105-118, 2001.

[17] H. Drexler, S. Kästner, A. Strobel, R. Studer, O. E. Brodde, and G. Hasenfuß, "Expression, activity and functional significance of inducible nitric oxide synthase in the failing human heart," Journal of the American College of Cardiology, vol. 32, no. 4, pp. 955-963, 1998. 
[18] K. Node, M. Kitakaze, F. Yoshihara, T. Sasaki, T. Kuzuya, and M. Hori, "Increased cardiac levels of nitric oxide in patients with chronic heart failure," American Journal of Cardiology, vol. 86, no. 4, pp. 474-477, 2000.

[19] V. L. Jakovljevic and D. M. Djuric, "The effects on nitric oxide synthase-versus lipoxygenase inhibition on coronary flow and nitrite outflow in isolated rat heart," General Physiology and Biophysics, vol. 24, no. 2, pp. 199-207, 2005.

[20] H. Cai and D. G. Harrison, "Endothelial dysfunction in cardiovascular diseases: the role of oxidant stress," Circulation Research, vol. 87, no. 10, pp. 840-844, 2000.

[21] M. Y. Ali, C. Y. Ping, Y.-Y. P. Mok et al., "Regulation of vascular nitric oxide in vitro and in vivo; a new role for endogenous hydrogen sulphide?" British Journal of Pharmacology, vol. 149, no. 6, pp. 625-634, 2006.

[22] H. Laggner, M. K. Muellner, S. Schreier et al., "Hydrogen sulphide: a novel physiological inhibitor of LDL atherogenic modification by HOCl," Free Radical Research, vol. 41, no. 7, pp. 741-747, 2007.

[23] M. Whiteman, J. S. Armstrong, S. H. Chu et al., "The novel neuromodulator hydrogen sulfide: an endogenous peroxynitrite "scavenger"?" Journal of Neurochemistry, vol. 90, no. 3, pp. 765-768, 2004.

[24] M. Whiteman, N. S. Cheung, Y.-Z. Zhu et al., "Hydrogen sulphide: a novel inhibitor of hypochlorous acid-mediated oxidative damage in the brain?" Biochemical and Biophysical Research Communications, vol. 326, no. 4, pp. 794-798, 2005.

[25] M. Whiteman, L. Li, I. Kostetski et al., "Evidence for the formation of a novel nitrosothiol from the gaseous mediators nitric oxide and hydrogen sulphide," Biochemical and Biophysical Research Communications, vol. 343, no. 1, pp. 303-310, 2006.

[26] N. G. Abraham, S. J. Peterson, and W. H. Frishman, “Targeting heme oxygenase: therapeutic implications for diseases of the cardiovascular system," Cardiology in Review, vol. 17, no. 4, p. 191, 2009.

[27] M. Bauer, K. Huse, U. Settmacher, and R. A. Claus, "The heme oxygenase-carbon monoxide system: regulation and role in stress response and organ failure," Intensive Care Medicine, vol. 34, no. 4, pp. 640-648, 2008.

[28] V. Zivkovic, V. Jakovljevic, D. Djordjevic, M. Vuletic, N. Barudzic, and D. Djuric, "The effects of homocysteine-related compounds on cardiac contractility, coronary flow, and oxidative stress markers in isolated rat heart," Molecular and Cellular Biochemistry, vol. 370, no. 1-2, pp. 59-67, 2012.

[29] H. Ohkawa, N. Ohishi, and K. Yagi, "Assay for lipid peroxides in animal tissues by thiobarbituric acid reaction," Analytical Biochemistry, vol. 95, no. 2, pp. 351-358, 1979.

[30] L. C. Green, D. A. Wagner, J. Glogowski, P. L. Skipper, J. S. Wishnok, and S. R. Tannenbaum, "Analysis of nitrate, nitrite, and $[15 \mathrm{~N}]$ nitrate in biological fluids," Analytical Biochemistry, vol. 126, no. 1, pp. 131-138, 1982.

[31] C. Auclair and E. Voisin, "Nitroblue tetrazolium reduction," in Handbook of Methods for Oxygen Radical Research, R. A. Greenwald, Ed., pp. 123-132, CRC Press, Boca Raton, Fla, USA, 1985.

[32] E. Pick and Y. Keisari, "A simple colorimetric method for the measurement of hydrogen peroxide produced by cells in culture," Journal of Immunological Methods, vol. 38, no. 1-2, pp. 161-170, 1980.
[33] K. S. Moshal, M. Kumar, N. Tyagi et al., "Restoration of contractility in hyperhomocysteinemia by cardiac-specific deletion of NMDA-R1," American Journal of Physiology: Heart and Circulatory Physiology, vol. 296, no. 3, pp. H887-H892, 2009.

[34] X. Gao, X. Xu, J. Pang et al., "NMDA receptor activation induces mitochondrial dysfunction, oxidative stress and apoptosis in cultured neonatal rat cardiomyocytes," Physiological Research, vol. 56, no. 5, pp. 559-569, 2007.

[35] K. S. Moshal, S. M. Tipparaju, T. P. Vacek et al., "Mitochondrial matrix metalloproteinase activation decreases myocyte contractility in hyperhomocysteinemia," American Journal of Physiology: Heart and Circulatory Physiology, vol. 295, no. 2, pp. H890-H897, 2008.

[36] F. Y. Chen, Y. H. Guo, W. Gao, X. H. Feng, L. Chen, and C. S. Tang, "Effect of hyperhomocysteinemia on cardiac remodeling in rats," Beijing Da Xue Xue Bao, vol. 38, no. 2, pp. 179-183, 2006.

[37] C. R. de Andrade, C. R. Tirapelli, R. Haddad et al., "Hyperhomocysteinemia induced by feeding rats diets rich in dlhomocysteine thiolactone promotes alterations on carotid reactivity independent of arterial structure," Vascular Pharmacology, vol. 51, no. 4, pp. 291-298, 2009.

[38] H. Jakubowski, L. Zhang, A. Bardeguez, and A. Aviv, "Homocysteine thiolactone and protein homocysteinylation in human endothelial cells implications for atherosclerosis," Circulation Research, vol. 87, no. 1, pp. 45-51, 2000.

[39] H. Wang, M. Yoshizumi, K. Lai et al., "Inhibition of growth and p21(ras) methylation in vascular endothelial cells by homocysteine but not cysteine," The Journal of Biological Chemistry, vol. 272, no. 40, pp. 25380-25385, 1997.

[40] K. A. Hajjar, "Homocysteine-induced modulation of tissue plasminogen activator binding to its endothelial cell membrane receptor," Journal of Clinical Investigation, vol. 91, no. 6, pp. 2873-2879, 1993.

[41] G. Starkebaum and J. M. Harlan, "Endothelial cell injury due to copper-catalyzed hydrogen peroxide generation from homocysteine," Journal of Clinical Investigation, vol. 77, no. 4, pp. 1370-1376, 1986.

[42] A. Miller, V. Mujumdar, L. Palmer, J. D. Bower, and S. C. Tyagi, "Reversal of endocardial endothelial dysfunction by folic acid in homocysteinemic hypertensive rats," American Journal of Hypertension, vol. 15, no. 2, pp. 157-163, 2002.

[43] H. S. Sood, M. J. Cox, and S. C. Tyagi, "Generation of nitrotyrosine precedes activation of metalloproteinase in myocardium of hyperhomocysteinemic rats," Antioxidants and Redox Signaling, vol. 4, no. 5, pp. 799-804, 2002.

[44] M. S. Muntzel, T. Joseph, and O. Onwumere, "Acute homocysteine administration does not elevate sympathetic nerve activity in rats," Atherosclerosis, vol. 184, no. 2, pp. 290-294, 2006.

[45] I. A. Sammut, R. Foresti, J. E. Clark et al., "Carbon monoxide is a major contributor to the regulation of vascular tone in aortas expressing high levels of haeme oxygenase-1," British Journal of Pharmacology, vol. 125, no. 7, pp. 1437-1444, 1998.

[46] H. Jakubowski, "Homocysteine thiolactone: metabolic origin and protein homocysteinylation in humans," Journal of Nutrition, vol. 130, pp. 377-381, 2000.

[47] H. Jakubowski, "Protein homocysteinylation: possible mechanism underlying pathological consequences of elevated homocysteine levels," The FASEB Journal, vol. 13, no. 15, pp. 22772283, 1999 . 
[48] R. Głowacki and H. Jakubowski, "Cross-talk between Cys34 and lysine residues in human serum albumin revealed by $\mathrm{N}$ homocysteinylation," The Journal of Biological Chemistry, vol. 279, no. 12, pp. 10864-10871, 2004.

[49] J. Perła-Kaján, Ł. Marczak, L. Kaján, P. Skowronek, T. Twardowski, and H. Jakubowski, "Modification by homocysteine thiolactone affects redox status of cytochrome c," Biochemistry, vol. 46, no. 21, pp. 6225-6231, 2007.

[50] D. L. Sauls, E. Lockhart, M. E. Warren, A. Lenkowski, S. E. Wilhelm, and M. Hoffman, "Modification of fibrinogen by homocysteine thiolactone increases resistance to fibrinolysis: a potential mechanism of the thrombotic tendency in hyperhomocysteinemia," Biochemistry, vol. 45, no. 8, pp. 2480-2487, 2006.

[51] M. Sibrian-Vazquez, J. O. Escobedo, S. Lim, G. K. Samoei, and R. M. Strongin, "Homocystamides promote free-radical and oxidative damage to proteins," Proceedings of the National Academy of Sciences of the United States of America, vol. 107, no. 2, pp. 551-554, 2010.

[52] P. Paoli, F. Sbrana, B. Tiribilli et al., "Protein Nhomocysteinylation induces the formation of toxic amyloid-like protofibrils," Journal of Molecular Biology, vol. 400, no. 4, pp. 889-907, 2010.

[53] A. Undas, J. Perła, M. Łacinski, W. Trzeciak, R. Kaźmierski, and H. Jakubowski, "Autoantibodies against N-homocysteinylated proteins in humans: implications for atherosclerosis," Stroke, vol. 35, no. 6, pp. 1299-1304, 2004.

[54] H. Jakubowski, G. H. J. Boers, and K. A. Strauss, "Mutations in cystathionine $\beta$-synthase or methylenetetrahydrofolate reductase gene increase N-homocysteinylated protein levels in humans," The FASEB Journal, vol. 22, no. 12, pp. 4071-4076, 2008.

[55] A. Undas, M. Jankowski, M. Twardowska, A. Padjas, H. Jakubowski, and A. Szczeklik, "Antibodies to Nhomocysteinylated albumin as a marker for early-onset coronary artery disease in men," Thrombosis and Haemostasis, vol. 93, no. 2, pp. 346-350, 2005.

[56] H. Jakubowski, "Anti-N-homocysteinylated protein autoantibodies and cardiovascular disease," Clinical Chemistry and Laboratory Medicine, vol. 43, no. 10, pp. 1011-1014, 2005.

[57] G. Chwatko and H. Jakubowski, "The determination of homocysteine-thiolactone in human plasma," Analytical Biochemistry, vol. 337, no. 2, pp. 271-277, 2005.

[58] G. Chwatko, G. H. J. Boers, K. A. Strauss, D. M. Shih, and H. Jakubowski, "Mutations in methylenetetrahydrofolate reductase or cystathionine $\beta$-syntase gene, or a high-methionine diet, increase homocysteine thiolactone levels in humans and mice," The FASEB Journal, vol. 21, no. 8, pp. 1707-1713, 2007.

[59] H. Jakubowski, "The determination of homocysteinethiolactone in biological samples," Analytical Biochemistry, vol. 308, no. 1, pp. 112-119, 2002.

[60] D. V. Abramochkin, N. N. Haertdinov, M. V. Porokhnya, A. L. Zefirov, and G. F. Sitdikova, "Carbon monoxide affects electrical and contractile activity of rat myocardium," Journal of Biomedical Science, vol. 18, no. 1, article 40, 2011.

[61] M. Bucci, A. Papapetropoulos, V. Vellecco et al., "cGMPdependent protein kinase contributes to hydrogen sulfidestimulated vasorelaxation," PLoS One, vol. 7, no. 12, Article ID e53319, 2012.

[62] Y. E. Huang, Z. H. Tang, W. Xie et al., "Endogenous hydrogen sulfide mediates the cardioprotection induced by ischemic postconditioning in the early reperfusion phase," Experimental and Therapeutic Medicine, vol. 4, no. 6, pp. 1117-1123, 2012.

[63] D. Djurić, A. Vušanović, and V. Jakovljević, “The effects of folic acid and nitric oxide synthase inhibition on coronary flow and oxidative stress markers in isolated rat heart," Molecular and Cellular Biochemistry, vol. 300, no. 1-2, pp. 177-183, 2007.

[64] V. L. Jakovljevic, D. Z. Djordjevic, and D. M. Djuric, "The effects of vitamin $\mathrm{C}$ and nitric oxide synthase inhibition on coronary flow and oxidative stress markers in isolated rat heart," General Physiology and Biophysics, vol. 30, no. 3, pp. 293-300, 2011.

[65] Y. Kimura and H. Kimura, "Hydrogen sulfide protects neurons from oxidative stress," The FASEB Journal, vol. 18, no. 10, pp. 1165-1167, 2004.

[66] B. Geng, L. Chang, C. Pan et al., "Endogenous hydrogen sulfide regulation of myocardial injury induced by isoproterenol," Biochemical and Biophysical Research Communications, vol. 318, no. 3, pp. 756-763, 2004.

[67] K. Módis, A. Asimakopoulou, C. Coletta, A. Papapetropoulos, and C. Szabo, "Oxidative stress suppresses the cellular bioenergetic effect of the 3-mercaptopyruvate ulfurtransferase/hydrogen sulfide pathway," Biochemical and Biophysical Research Communications, vol. 433, no. 4, pp. 401-407, 2013.

[68] Y. Kimura, Y.-I. Goto, and H. Kimura, "Hydrogen sulfide increases glutathione production and suppresses oxidative stress in mitochondria," Antioxidants and Redox Signaling, vol. 12, no. 1, pp. 1-13, 2010.

[69] N. Nagahara, T. Nirasawa, T. Yoshii, and Y. Niimura, "Is novel signal transducer sulfur oxide involved in the redox cycle of persulfide at the catalytic site cysteine in a stable reaction intermediate of mercaptopyruvate sulfurtransferase?" Antioxidants and Redox Signaling, vol. 16, no. 8, pp. 747-753, 2012.

[70] N. Nagahara, T. Yoshii, Y. Abe, and T. Matsumura, "Thioredoxin-dependent enzymatic activation of mercaptopyruvate sulfurtransferase: an intersubunit disulfide bond serves as a redox switch for activation," The Journal of Biological Chemistry, vol. 282, no. 3, pp. 1561-1569, 2007.

[71] Y. Mikami, N. Shibuya, Y. Kimura, N. Nagahara, Y. Ogasawara, and H. Kimura, "Thioredoxin and dihydrolipoic acid are required for 3-mercaptopyruvate sulfurtransferase to produce hydrogen sulfide," Biochemical Journal, vol. 439, no. 3, pp. 479485, 2011.

[72] M. Kajimura, M. Shimoyama, S. Tsuyama et al., "Visualization of gaseous monoxide reception by soluble guanylate cyclase in the rat retina," The FASEB Journal, vol. 17, no. 3, pp. 506-508, 2003.

[73] H. Soni, P. Patel, A. C. Rath, M. Jain, and A. A. Mehta, "Cardioprotective effect with carbon monoxide releasing molecule2 (CORM-2) in isolated perfused rat heart: role of coronary endothelium and underlying mechanism," Vascular Pharmacology, vol. 53, no. 1-2, pp. 68-76, 2010. 


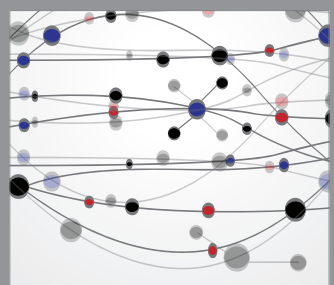

The Scientific World Journal
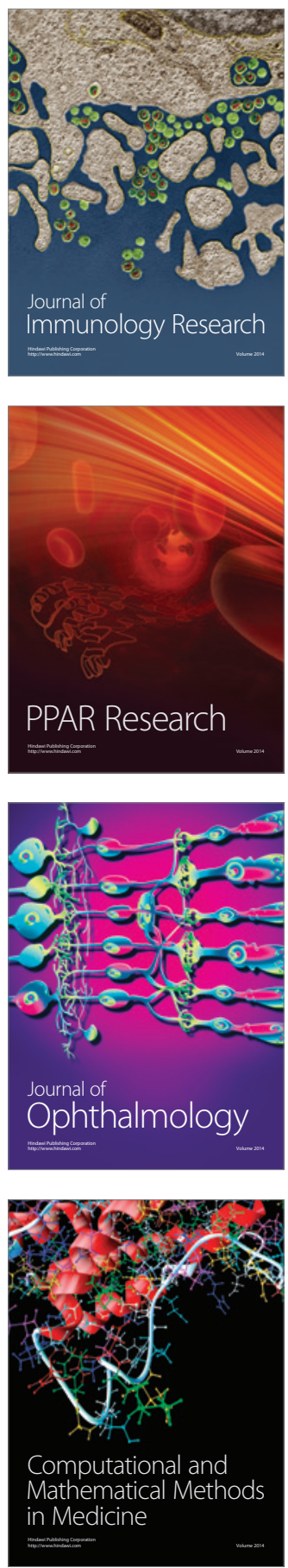

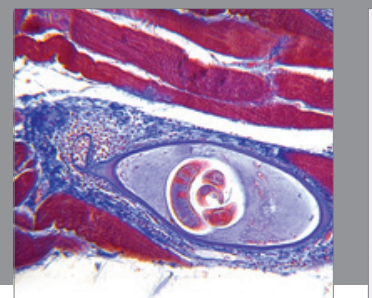

Gastroenterology

Research and Practice
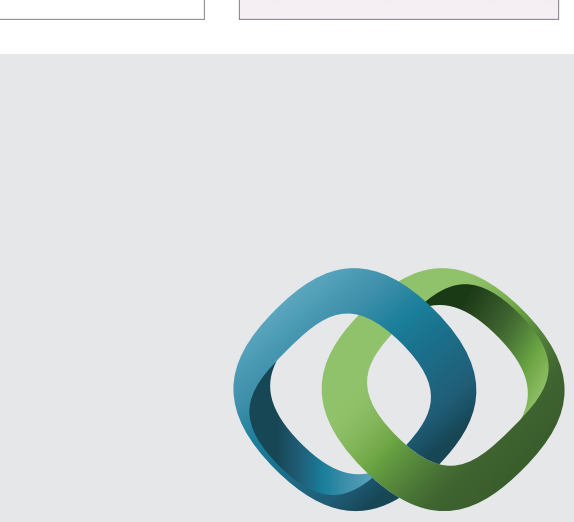

\section{Hindawi}

Submit your manuscripts at

http://www.hindawi.com
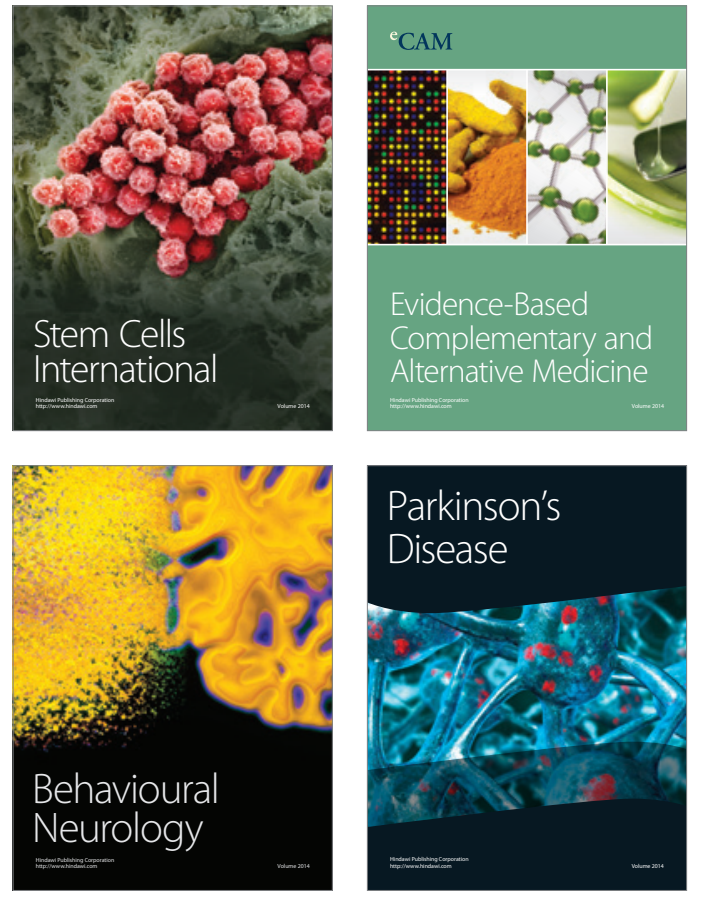
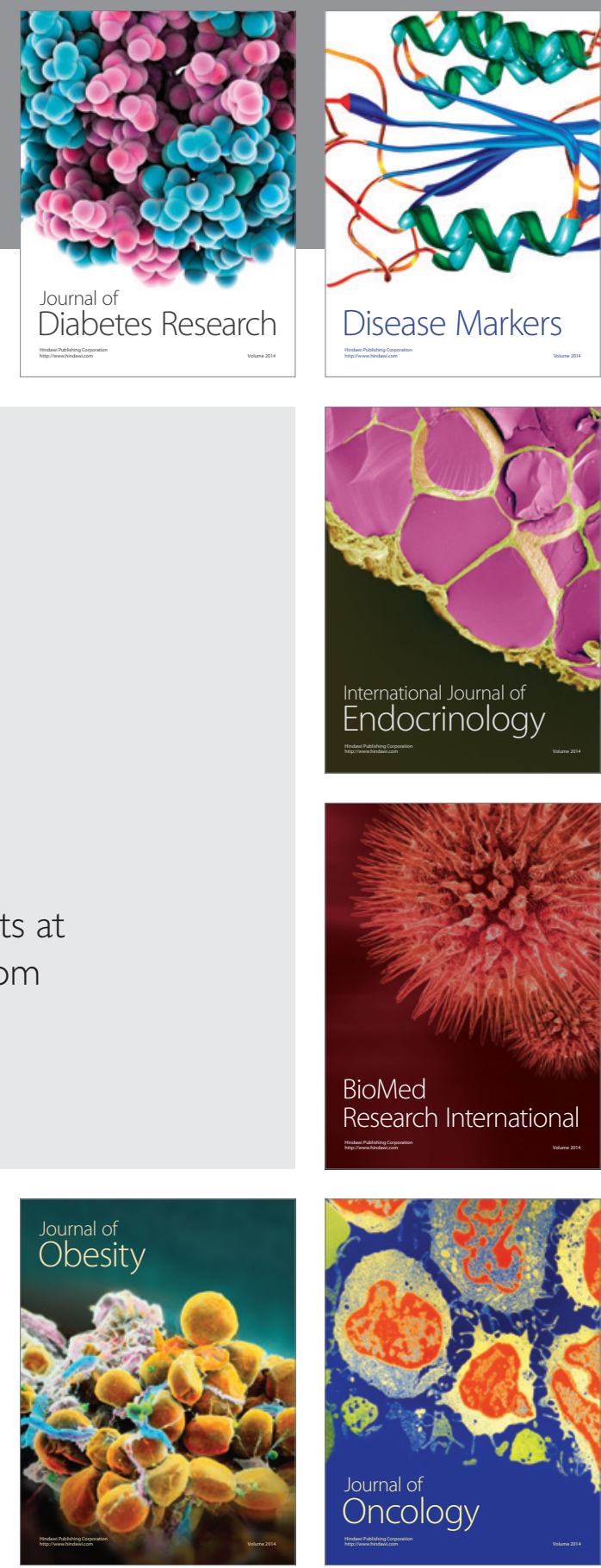

Disease Markers
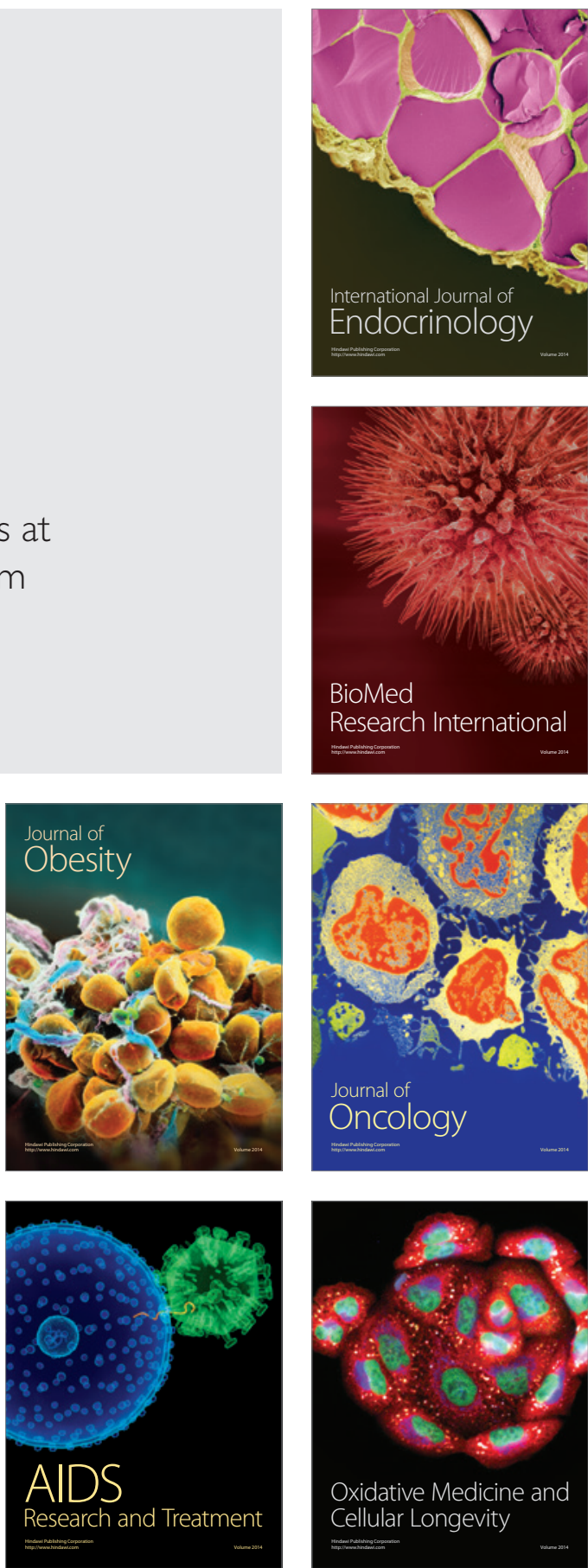